\title{
Supplementary material:MATLAB ${ }^{\circledR}-$ codes
}

\author{
Roland SCHIERHOLZ ${ }^{a *}$ \\ ${ }^{a}$ Technische Universität Darmstadt Germany. E-mail: rolandschierholz@gmx.de
}

\section{Introduction}

This material contains the MATLAB ${ }^{\circledR}$-codes for review process and/or to be provided for interested readers. The codes are divided into different parts to display in shorter form for readability. So the position, where a part should be included, is marked with > > Part. Other calculations also repeat often so in this case only the comment line and subsequent ... are shown to imply that the similar calculation as already described above follows. Following abbrevations are used: twin operation (TO), Nanodomain (ND), nanodomain wall (NDW), microdomain wall (MDW).

\section{MATLAB-code PART I \\ Calculation of twins}

2.1. Tetragonal $90^{\circ}$-wall in (110)

function $\mathrm{zolz}=\operatorname{tetra}(\mathrm{h} 1, \mathrm{k} 1, \mathrm{l} 1, \mathrm{~h} 2, \mathrm{k} 2, \mathrm{l} 2)$

$\%$ lattice parameters

$\mathrm{a}=4.04 ; \mathrm{b}=\mathrm{a} ; \mathrm{c}=4.14 ;$

$\%$ lattice vectors in cartesian space

$\mathrm{c}=[\mathrm{c} ; 0 ; 0]$;

$\mathrm{b}=[0 ; 0 ; \mathrm{b}]$;

$\mathrm{a}=[0 ; \mathrm{a} ; 0]$;

reciprocal lattice

$\operatorname{ar}=\operatorname{cross}(b, c) /(\operatorname{dot}(a, \operatorname{cross}(b, c)))$;

$\cdots$

PREPRINT: Journal of Applied Crystallography

A Journal of the International Union of Crystallography 
$\%$ normal vector of (101)-domain wall

$\mathrm{n}=\mathrm{ar}+\mathrm{cr}$

$\%$ rotation about $[001]$ to align $\mathrm{n}||[110]$

delta $=\operatorname{atan}((\mathrm{n}(1) / \mathrm{n}(2)-1) /(\mathrm{n}(1) / \mathrm{n}(2)+1))$;

$\operatorname{rot} 1=[\cos ($ delta $)-\sin ($ delta $) 0 ; \ldots$

$\sin ($ delta $) \cos ($ delta $) 0 ; \ldots$

$\left.\begin{array}{lll}0 & 0 & 1\end{array}\right]$;

$\%$ lattice of domain 1

$\mathrm{a} 1=\operatorname{rot} 1 * \mathrm{a}$;

...

$\%$ TO 2 fold rotation about [110]

$\mathrm{R} 110=\left[\begin{array}{lllllllll}0 & 1 & 0 ; & 1 & 0 & 0 ; & 0 & 0 & -1\end{array}\right]$;

$\%$ lattice of domain 2

...

$\%$ reciprocal lattice for domain 1 and 2

...

$\%$ coordinates in ZOLZ in this form

$\%$ ! only for perpendicular base vectors!

$\mathrm{x}=\left[\begin{array}{lll}\mathrm{h} 1 & \mathrm{k} 1 & \mathrm{l} 1\end{array}\right] / \operatorname{norm}\left(\left[\begin{array}{lll}\mathrm{h} 1 & \mathrm{k} 1 & 11\end{array}\right]\right)$;

$\mathrm{y}=\left[\begin{array}{lll}\mathrm{h} 2 & \mathrm{k} 2 & 12\end{array}\right] / \operatorname{norm}\left(\left[\begin{array}{lll}\mathrm{h} 2 & \mathrm{k} 2 & 12\end{array}\right]\right)$;

$\%$ zone axis [uvw]

$\mathrm{uvw}=\operatorname{cross}(\mathrm{x}, \mathrm{y})$;

2.2. Rhombohedral $71^{\circ}$-wall in (110)

function $\mathrm{zolz}=\operatorname{rhombo} 110(\mathrm{~h} 1, \mathrm{k} 1, \mathrm{l} 1, \mathrm{~h} 2, \mathrm{k} 2,12)$

$\%$ lattice parameters (monoclinic set up)

$\mathrm{a}=[5.79] ; \mathrm{b}=[5.75] ; \mathrm{c}=[4.08] ;$

beta $=[90.56] ;$

$\%$ domain 1 (100)m||(-1-10)c

$\mathrm{a} 1=[-\mathrm{a} / \mathrm{sqrt}(2) * \sin ($ beta $/ 180 * \mathrm{pi}) ; \ldots$

$-\mathrm{a} / \operatorname{sqrt}(2) * \sin ($ beta $/ 180 * \mathrm{pi}) ; \ldots$

$\mathrm{a} * \cos (\mathrm{beta} / 180 * \mathrm{pi})]$;

$\mathrm{b} 1=[\mathrm{b} / \mathrm{sqrt}(2) ;-\mathrm{b} / \mathrm{sqrt}(2) ; 0]$;

$\mathrm{c} 1=[0 ; 0 ; \mathrm{c}]$;

$\% 2$ fold rotation about [110]

$\mathrm{R} 110=\left[\begin{array}{lllllllll}0 & 1 & 0 ; & 1 & 0 & 0 ; & 0 & 0 & -1\end{array}\right]$;

$\%$ lattice of domain 2

$\mathrm{a} 2=\mathrm{R} 110 * \mathrm{a} 1 ; \ldots$

$\%$ reciprocal lattice

...

$\%$ zone axis [uvw]

..

function $\mathrm{zolz}=\operatorname{rhombo} 100(\mathrm{~h} 1, \mathrm{k} 1, \mathrm{l} 1, \mathrm{~h} 2, \mathrm{k} 2, \mathrm{l} 2)$

$\%$ lattice parameters in monoclinic setup

...

IUCr macros version 2.1.5: 2012/03/07 


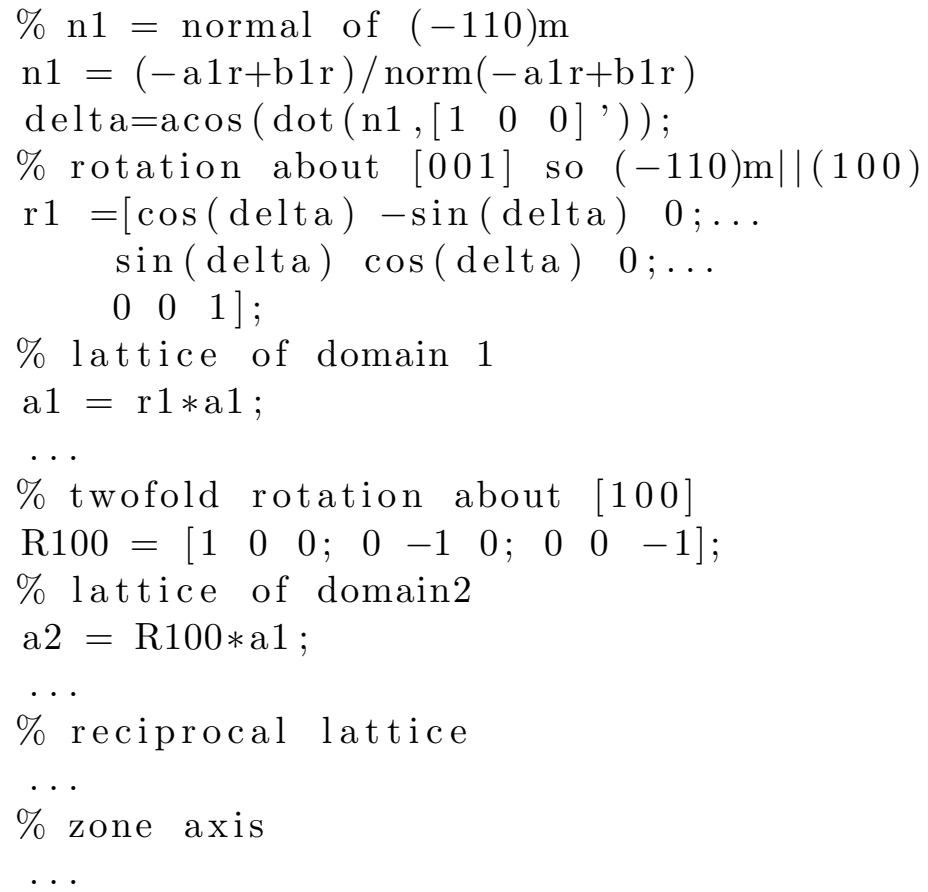

\section{Part II}

Calculation of reflection positions in ZOLZ for Fig. 2, 3 and 4

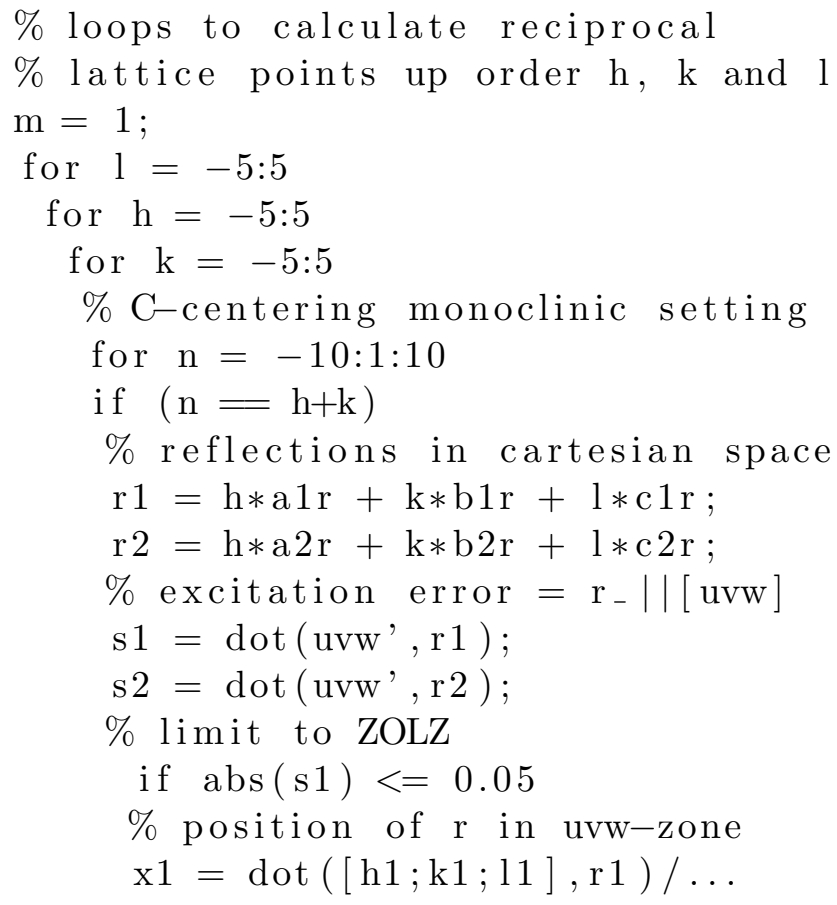




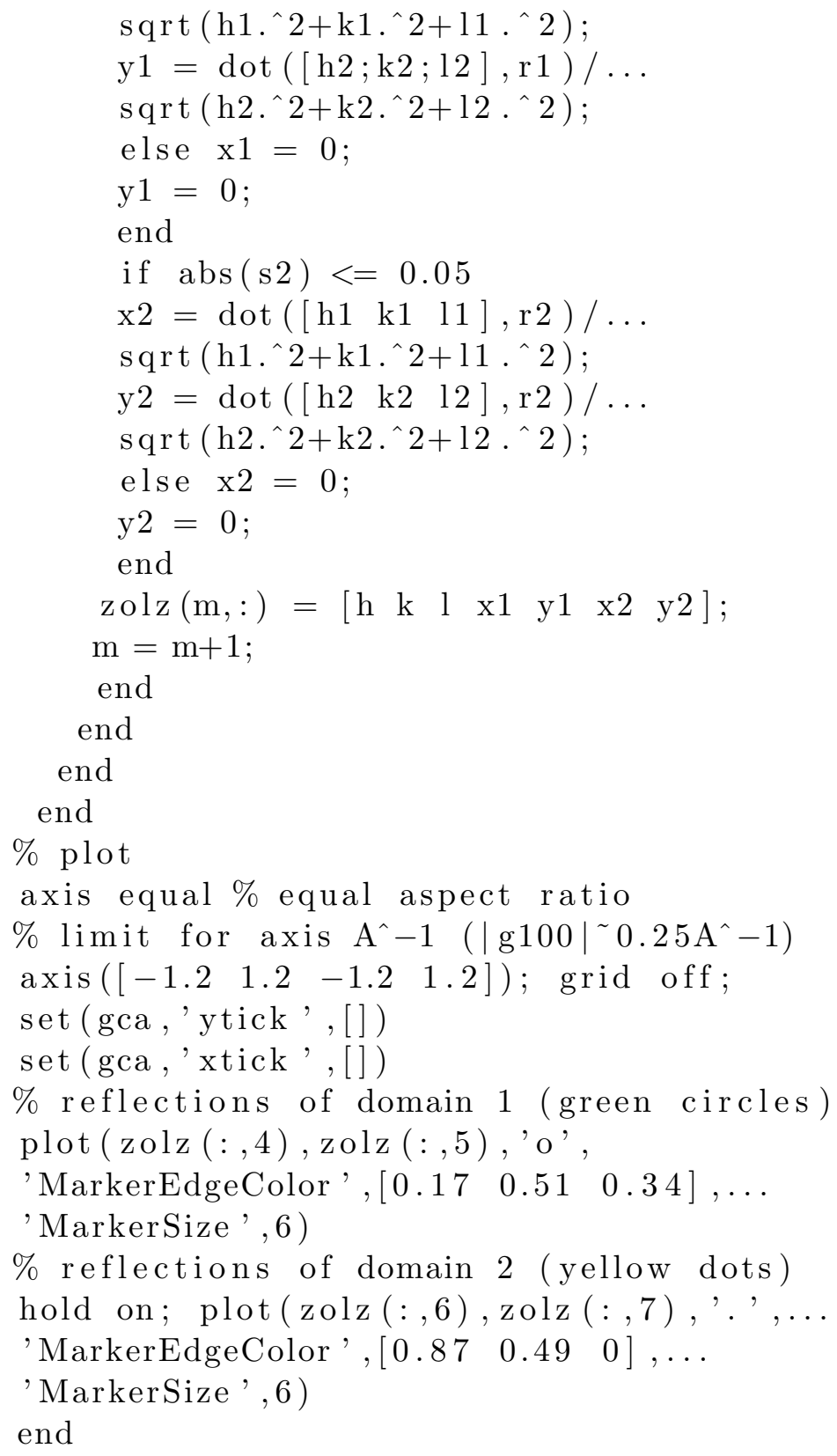

4. Part III: calculation of $s$ for Fig. 5

4.1. Tetragonal $90^{\circ}$-wall

function $d g=$ splitting -tetra()

$\mathrm{m}=1$

for $\mathrm{dc}=0.0: 0.005: 0.15$;

IUCr macros version 2.1.5: 2012/03/07 


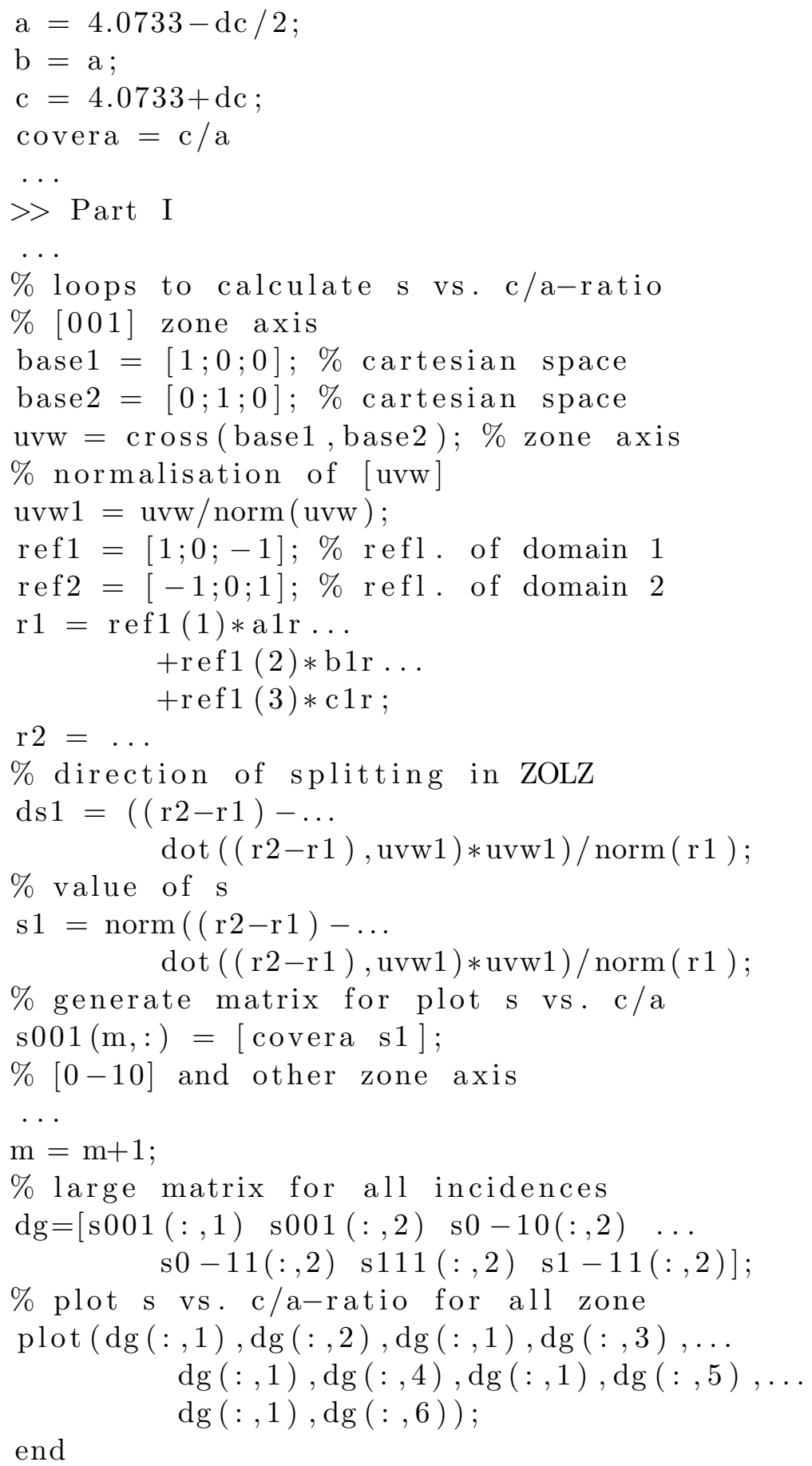

function $\mathrm{dg}=$ splitting_rhombo110()

$\mathrm{m}=1$;

for $\mathrm{r}=0: 0.05: 1$;

alpha $=(90-\mathrm{r}) / 180 * \mathrm{pi}$;

IUCr macros version 2.1.5: 2012/03/07 


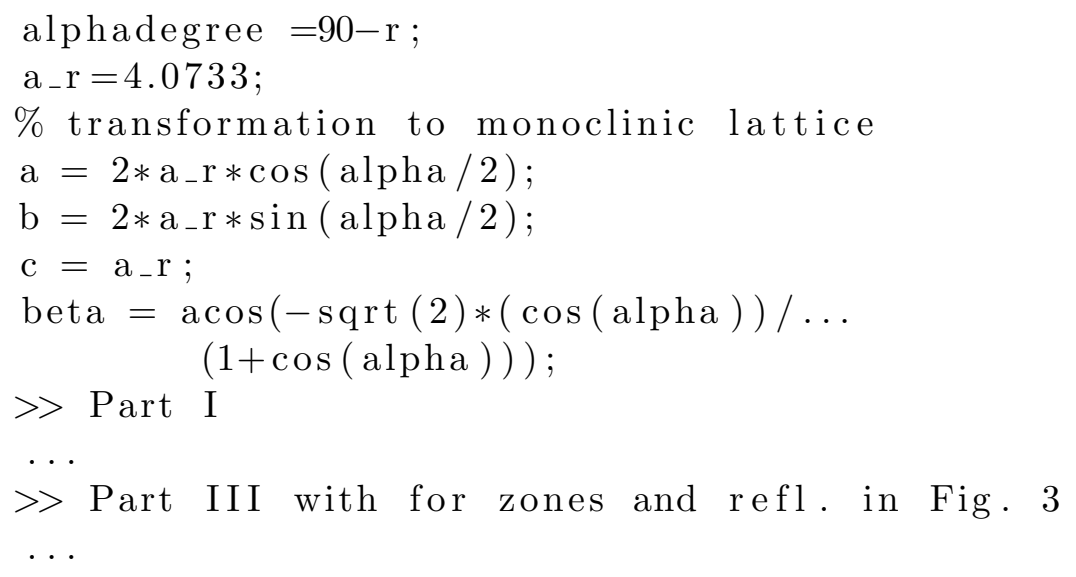

4.1.2. Rhombohedral $109^{\circ}$-wall (100) For rhombohedral (100)-domain walls $s$ can be calculated in a similar way for the reflections indexed in Fig. 4. Only the base vectors, indices of reflections and the twin operation, according to Part I need to be adapted.

\section{Part IV \\ Multidomain configurations}

This is a very simple approach. Only geometrical stiff lattices are transformed by twin operations and the mismatch angles are calculated. The first type of angles given expresses the roughness of the microdomain wall (MDW). This is the angle between the surface normals of crystallographic planes that represent the MDW for in the different nanodomains (ND). The second angle gives the missing wedge that is left inside the microdomain. This is calculated as the angle between the normals of the crystallographic planes of the nanodomains, that ideally should be parallel, after a series of twin operations ( $\mathrm{TO})$.

\subsection{Monoclinic $\{110\}$-mirror twins inside tetragonal domains}

function omega $=$ nanodomains $4 m m_{-} \_11$

$\%$ lattice parameters in monoclinic setup

IUCr macros version 2.1.5: 2012/03/07 


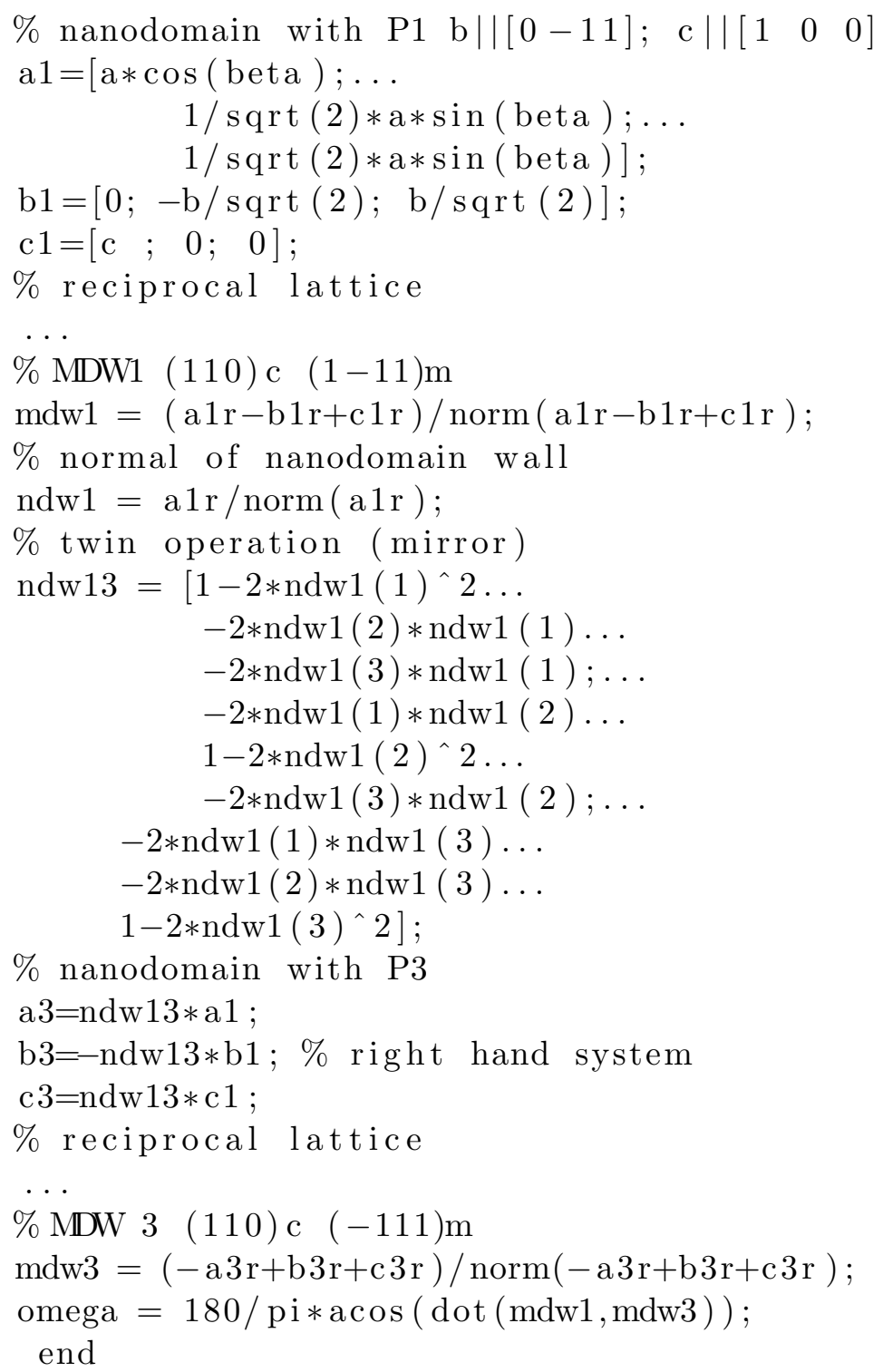

5.2. Monoclinic $\{100\}$-mirror twins inside tetragonal domains

function omega $=$ nanodomains $4 m_{-} m_{0} 010$

$\%$ lattice parameters in monoclinic setup

...

gamma $=\operatorname{atan}(\mathrm{a} / \mathrm{b})$

$\%$ orientation with $[110] \mathrm{m}|| \mathrm{z}$

$\mathrm{a} 1=[0 ; \mathrm{a} * \cos ($ gamma $) ; \mathrm{a} * \sin ($ gamma $)]$;

$\mathrm{b} 1=[0 ;-\mathrm{b} * \sin ($ gamma $) ; \mathrm{b} * \cos ($ gamma $)]$;

$\mathrm{c} 1=[\mathrm{c} * \sin ($ beta $) ; \ldots$

$1 / \operatorname{sqrt}(2) * \mathrm{c} * \cos ($ beta $) ; \ldots$

$1 / \operatorname{sqrt}(2) * \mathrm{c} * \cos ($ beta) $]$;

$\%$ reciprocal lattice

IUCr macros version 2.1.5: 2012/03/07 


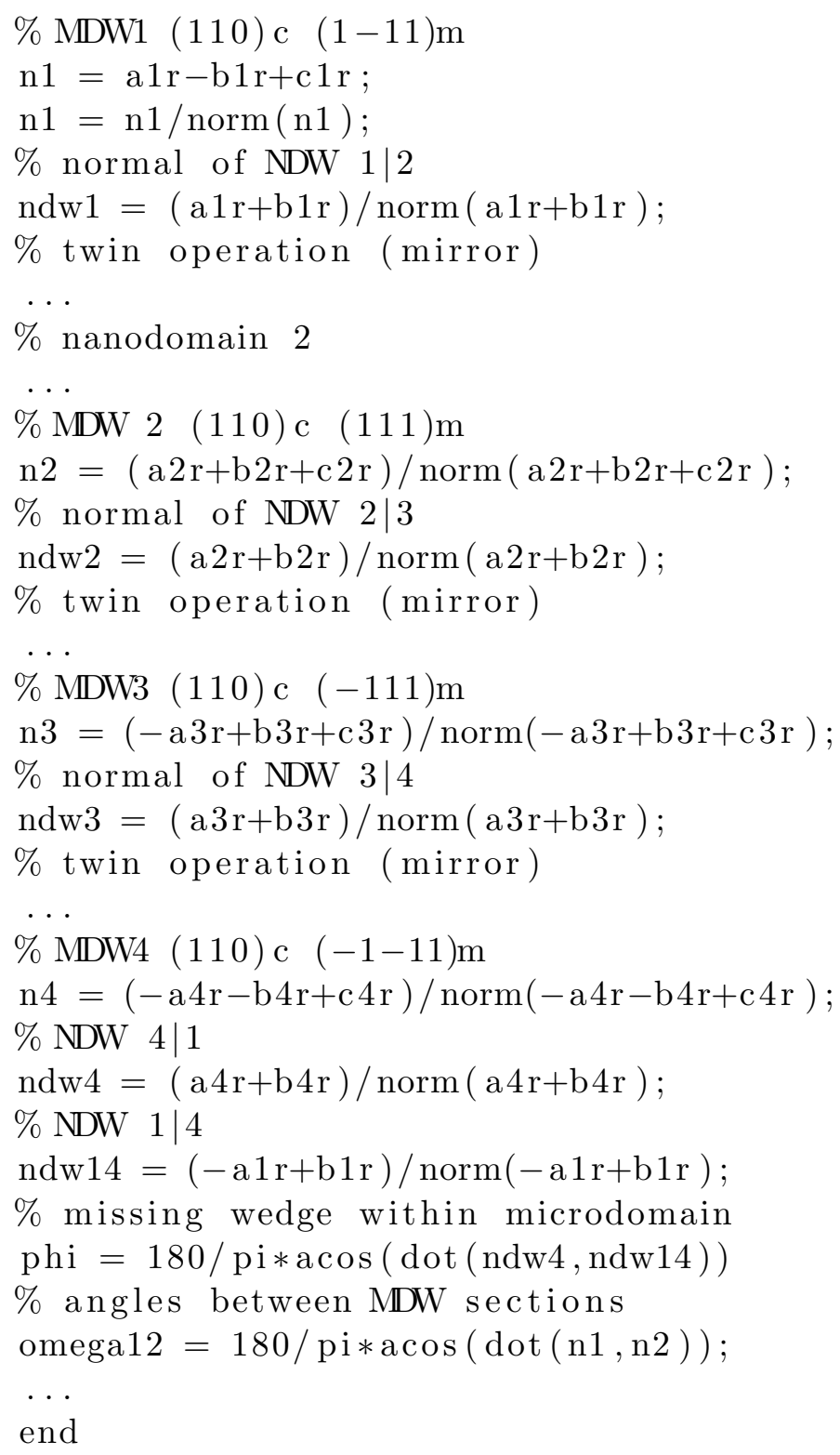

5.3. $90^{\circ}$-rotational nanotwins inside tetragonal domains

function omega $=$ nanodomains4mm_001R

$\%$ lattice parameters in monoclinic setup gamma $=\operatorname{atan}(\mathrm{a} / \mathrm{b})$

$\%$ orientation with c||[1 00$]$

$\%$ so twin operation is roation about [100]

$\mathrm{a} 1=[0 ; \mathrm{a} * \cos ($ gamma $) ; \mathrm{a} * \sin ($ gamma $)]$

$\mathrm{b} 1=[0 ;-\mathrm{b} * \sin ($ gamma $) ; \mathrm{b} * \cos ($ gamma $)]$

$\mathrm{bn}=-\mathrm{b} 1 / \operatorname{norm}(\mathrm{b} 1) ; \%$ for rotation matrix

$\mathrm{c} 1=[\mathrm{c} * \sin ($ beta $) ; 1 / \operatorname{sqrt}(2) * \mathrm{c} * \cos ($ beta $) ; 1 / \operatorname{sqrt}(2) * \mathrm{c} * \cos ($ beta $)]$;

$\%$ reciprocal lattice

IUCr macros version 2.1.5: 2012/03/07 


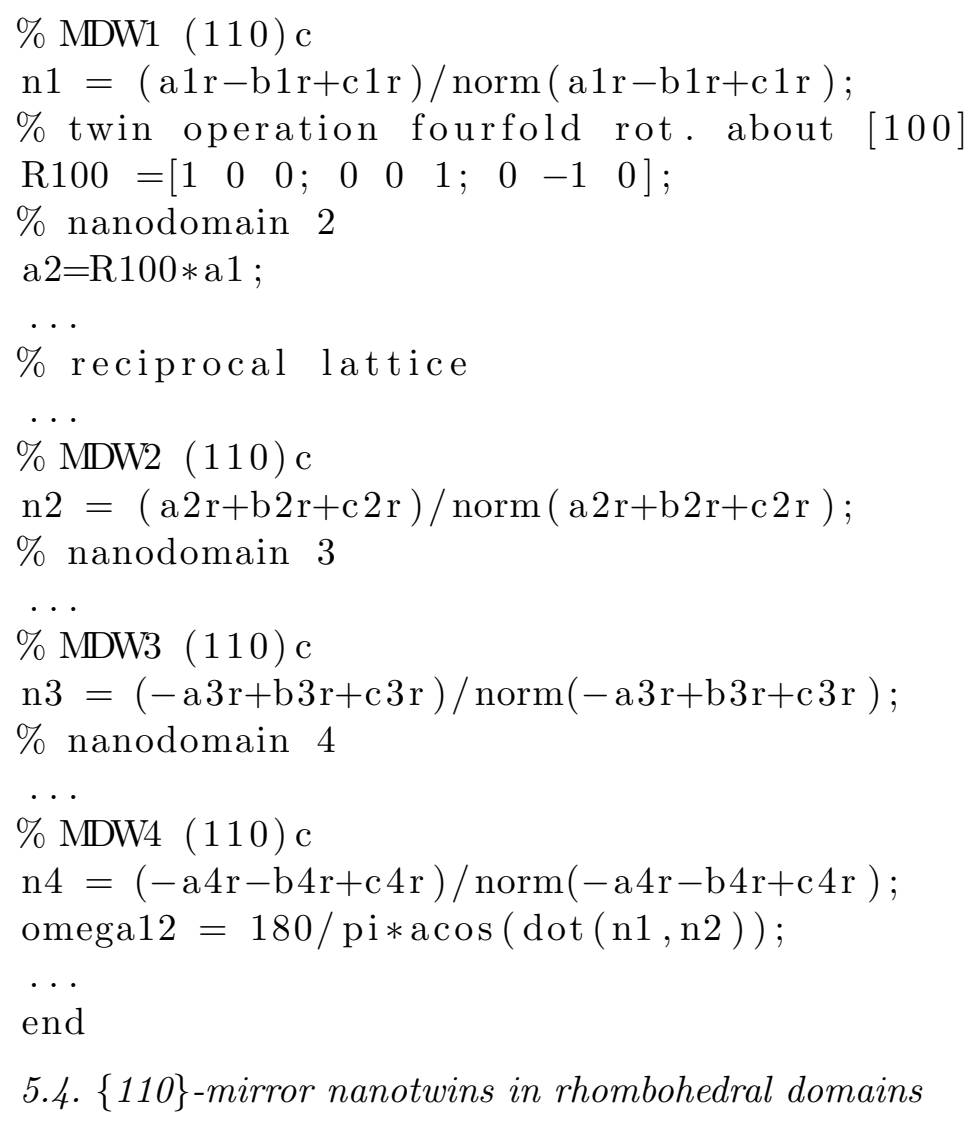

The programs are written for both $(100)_{c}$ and $(110)_{c}$ MDWs. The result not wanted should be commented.

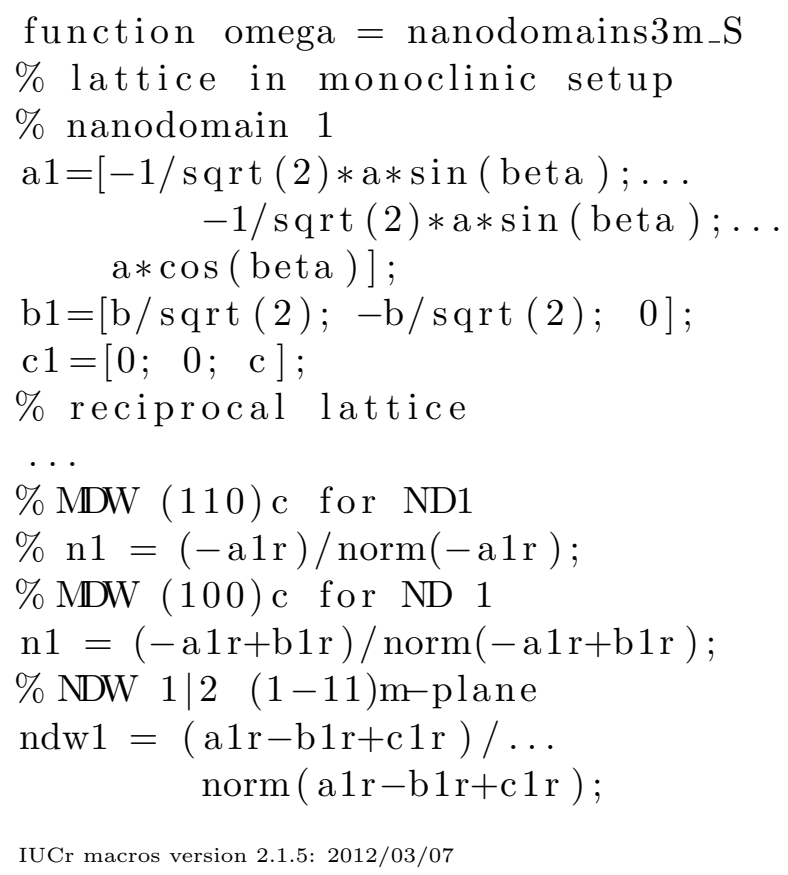




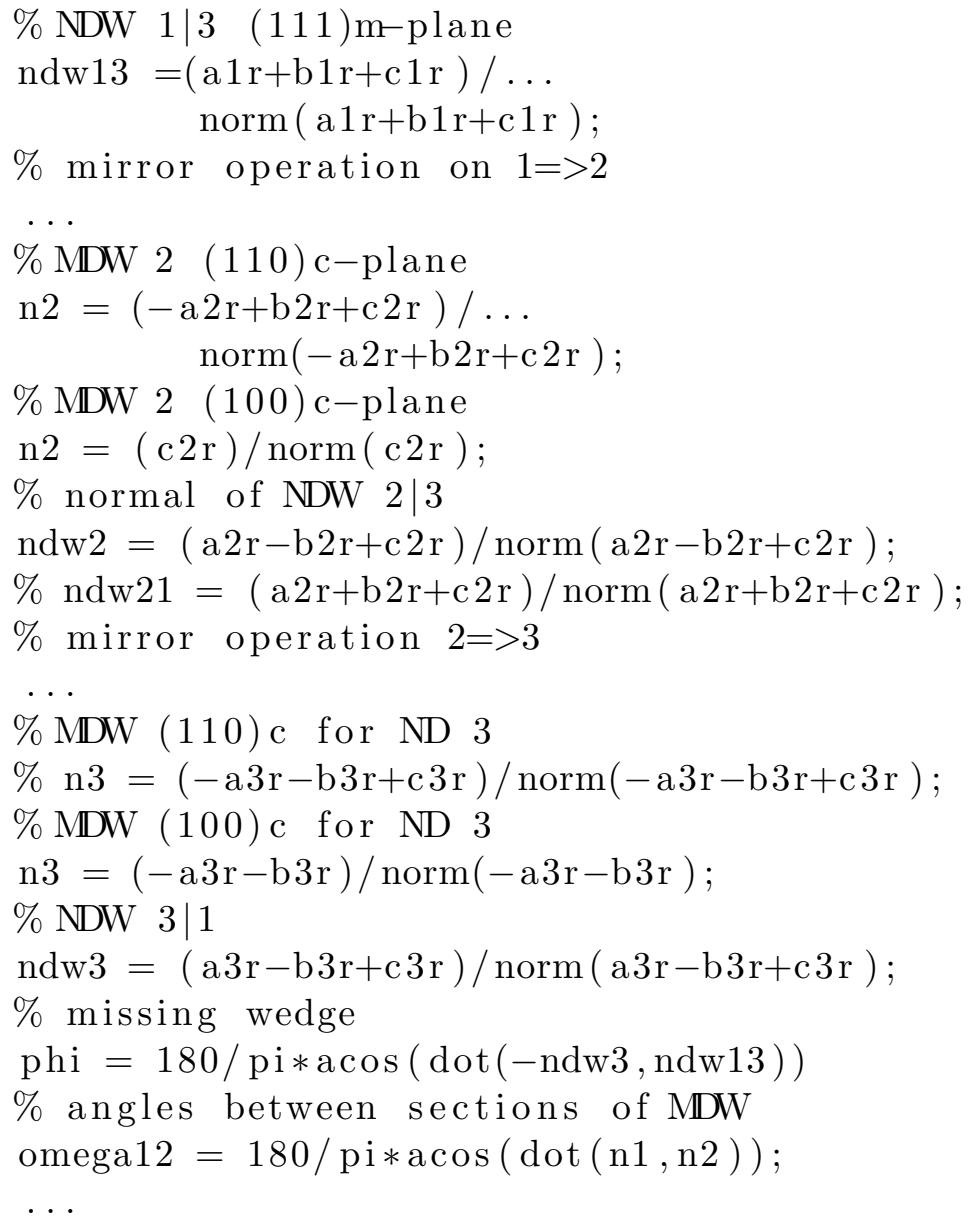

\section{5. $120^{\circ}$-rotational nanotwins}

function nanodomains3m_R()

$\%$ lattice in monoclinic setup

‥

$\mathrm{a} 1=[-1 / \operatorname{sqrt}(2) * \mathrm{a} * \sin ($ beta $) ; \ldots$

$-1 / \operatorname{sqrt}(2) * a * \sin ($ beta $) ; \ldots$ $\mathrm{a} * \cos ($ beta $)]$;

$\mathrm{b} 1=[\mathrm{b} / \operatorname{sqrt}(2) ;-\mathrm{b} / \operatorname{sqrt}(2) ; 0] ;$

$\mathrm{c} 1=[0 ; 0 ; \mathrm{c}]$;

$\%$ reciprocal lattice

...

$\%$ normal of $(-201) \mathrm{m}$ plane $(111) \mathrm{c}$

$\mathrm{n}=(-2 * \operatorname{ar}+\mathrm{cr}) / \operatorname{norm}(-2 * \operatorname{ar}+\mathrm{cr})$;

$\%[-101] \mathrm{m}=[111] \mathrm{c}$

$\%$ rotation about $[1-10]$

$\mathrm{r}=[1 / \operatorname{sqrt}(2) ;-1 / \operatorname{sqrt}(2) ; 0]$;

$\%$ to aligne $(-201) \mathrm{m}||(111)$

IUCr macros version 2.1.5: 2012/03/07 


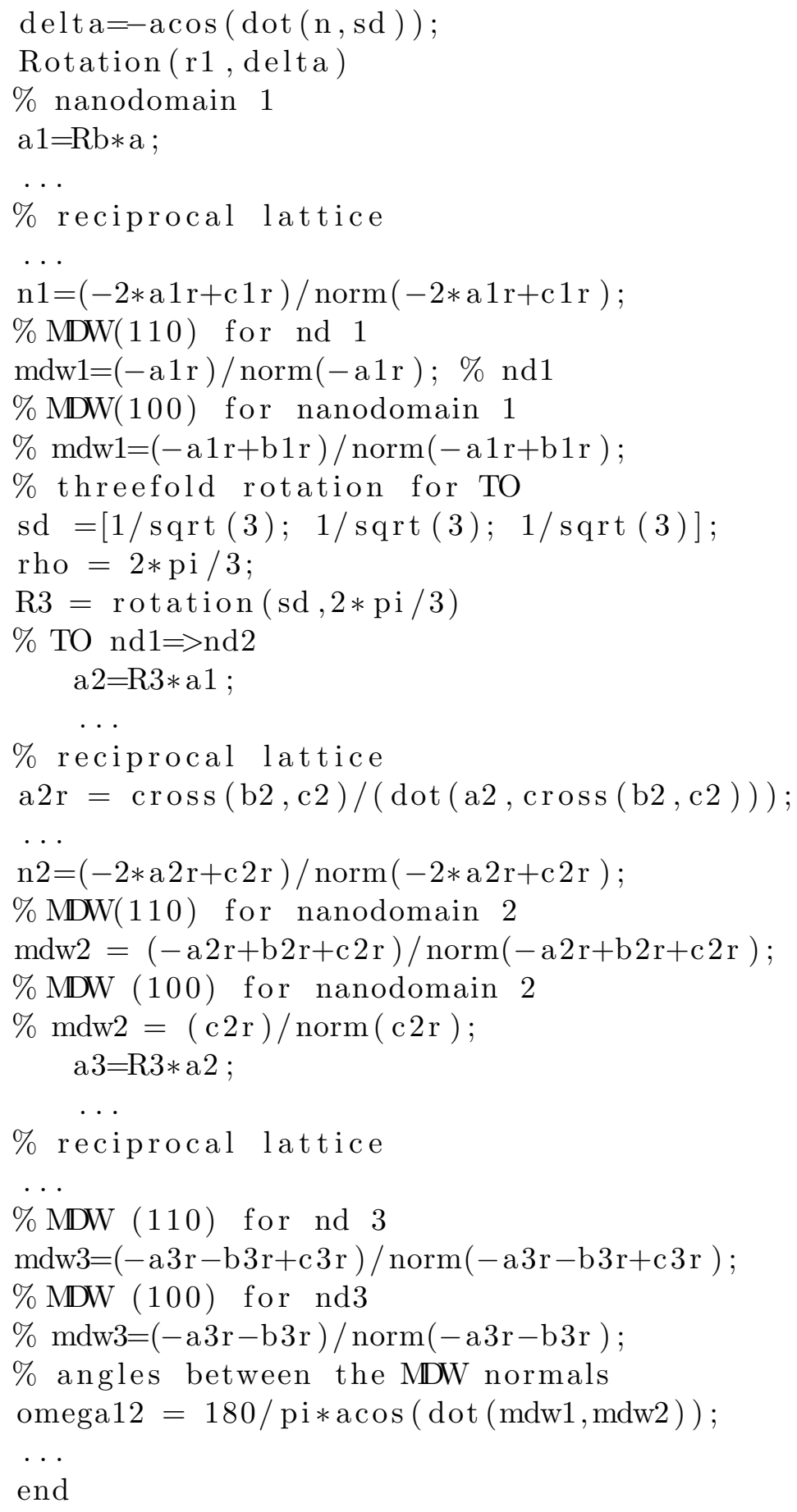

